\title{
ELABORAÇÃO DE UM BANCO DE DADOS DE MATERIAIS SEMICONDUTORES E CONDUTORES*
}

\author{
Manuela Arend Prediger ${ }^{1}$ \\ Tatiana Louise Avila de Campos Rocha
}

\section{Resumo}

Este trabalho teve como objetivo desenvolver um banco de dados com ênfase em materiais semicondutores e condutores para disponibilizar informações dos quatro principais grupos de materiais: metais, compósitos, cerâmicos e polímeros. Isto foi realizado através de uma seleção de materiais e definição de quais os mais adequados à área de semicondutores. Por intermédio de levantamentos bibliográficos em livros, periódicos e sites, foi possível compilar as características e as aplicações destes diferentes tipos de materiais. Assim, obteve-se um site que contém informações precisas e confiáveis e que está disponível àqueles que possuem interesse nesta área. Infere-se a partir do trabalho feito que o uso de materiais semicondutores faz-se cada vez mais necessário e crucial para satisfazer as exigências de equipamentos eletrônicos.

Palavras-chave: Materiais; Semicondutores; Banco de dados.

\section{DEVELOPMENT OF A DATABASE OF SEMICONDUCTORS AND CONDUCTORS MATERIALS}

\section{Abstract}

This work aimed to develop a database with emphasis on semiconductor and conductor materials to provide information of the major groups of materials: metals, composites, ceramics and polymers. The work was carried out by using materials selection and definition of the most used materials into the semiconductor area. Analyzing bibliographic surveys as books, journals and websites, it was possible to compile the characteristics and applications of these different types of materials. So, the site obtained contains accurate and reliable information and this is available to those who have interest in this area. It can be observed from the work that the use of semiconductor materials is increasingly necessary and crucial to satisfy the requirements of electronics equipment.

Keywords: Materials; Semiconductors; Database.

1 Graduanda em Engenharia de Materiais, Bolsista de Iniciação Científica, Núcleo de Caracterização de Materiais, Universidade do Vale do Rio dos Sinos, São Leopoldo, Rio Grande do Sul, Brasil.

2 Graduada em Química Industrial, Doutora em Ciência dos Materiais, Orientadora, Núcleo de Caracterização de Materiais, Universidade do Vale do Rio dos Sinos, São Leopoldo, Rio Grande do Sul, Brasil. 


\section{INTRODUÇÃO}

As excelentes propriedades elétricas dos semicondutores permitiram um acentuado crescimento na demanda por componentes eletrônicos, uma vez que os semicondutores são fundamentais na fabricação destes dispositivos, sendo capazes de exercer funções eletrônicas específicas [1]. A descoberta de dispositivos semicondutores deu origem à miniaturização de circuitos e é responsável pelo crescimento e surgimento acelerado de uma nova indústria [1]. Os benefícios apresentados pelos dispositivos semicondutores incluem dimensões reduzidas, menor consumo de energia e ausência de tempo de aquecimento [1]. A busca por miniaturização de dispositivos eletrônicos é tanta, que novos materiais e até mesmo novas arquiteturas são fundamentais para expandir pesquisas e o desenvolvimento de projetos inovadores.

Há quatro grupos de materiais, entre eles os materiais cerâmicos, que possuem boas propriedades térmicas, mecânicas e elétricas [2]. Estes materiais resistem a altas temperaturas e a ambientes agressivos mais do que os metais e os polímeros [1]. O silício, que é considerado um material cerâmico, é o mais utilizado na indústria eletrônica em função de suas excelentes propriedades materiais e de processamento, além de ser encontrado abundantemente na natureza [3]. Os materiais metálicos, que são condutores de calor e eletricidade extremamente bons. Além disso, em relação às suas características mecânicas, são relativamente rígidos, resistentes e dúcteis [1]. Como exemplo, cita-se o cobre, que é resistente à corrosão em vários meios, é maleável e só a prata possui condutividade elétrica melhor do que este material [4]. Entre os materiais poliméricos, que têm sido constantemente estudados por possuírem altos valores de condutividade elétrica, há o poliacetileno, que quando dopado, possui condutividade comparável à do cobre, porém a estabilidade e a processabilidade não são muito boas. Já a polianilina e o polipirrol possuem condutividade boa e, ainda, possuem boa estabilidade ambiental e excelente processabilidade [5]. E, por fim, os materiais compósitos, que são capazes que incorporar as melhores características de dois ou mais materiais para que possa ser obtido um único material com características melhoradas, que é o caso do compósito de Nanotubos de Carbono (NTC) com polipirrol, em que o polipirrol aumenta a condutividade elétrica do polímero resultante, e os Nanotubos de Carbono reforçam mecanicamente e estabilizam termicamente [6].

Baseando-se na ascensão da indústria de semicondutores e na importância que os materiais possuem nesta área, buscou-se criar um banco de dados eletrônico que deixa à disposição informações a respeito de materiais condutores e semicondutores.

\section{MATERIAIS E MÉTODOS}

Para o trabalho ser desenvolvido, primeiramente foi realizado uma capacitação geral para utilização do software de seleção de materiais, Ces EduPack, que disponibiliza uma extensa base de dados sobre os mais diversos materiais existentes. Em seguida, foram selecionados alguns materiais semicondutores e condutores de cada grupo (metais, compósitos, polímeros e cerâmicos) que melhor se enquadravam nos critérios propostos. Reunindo os materiais selecionados, fez-se um levantamento bibliográfico em sites, livros e periódicos dos polímeros semicondutores, cerâmicos semicondutores, metais e compósitos semicondutores. Tendo todas as informações encontradas, compilou-as e publicou-as. Por fim, 
editou-se o banco de dados de forma organizada, dividindo os materiais por grupos e disponibilizando suas características e aplicações.

\section{RESULTADOS E DISCUSSÃO}

O resultado obtido foi a criação de um banco de dados eletrônico que ficará à disposição dos interessados no assunto através do site do curso de Engenharia de Materiais da Unisinos e, está disponível através da página:

http://semicondutores.wix.com/materiais.

$\mathrm{O}$ banco de dados de materiais condutores e semicondutores foi criado com o intuito de auxiliar de forma rápida na busca por materiais desta área, uma vez que ao acessar a página inicial do banco de dados, é possível obter informações sobre o projeto que originou este trabalho, além de uma breve introdução sobre cada grupo dos materiais. Ao clicar sob o grupo escolhido (polímeros, metais, cerâmicos ou compósitos), têm-se os materiais selecionados à área de semicondutores e suas respectivas características e aplicações.

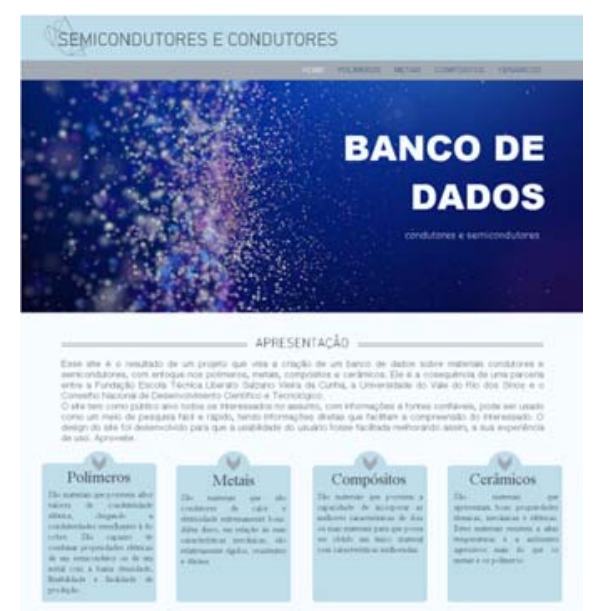

Figura 1. Representação da página inicial no site.

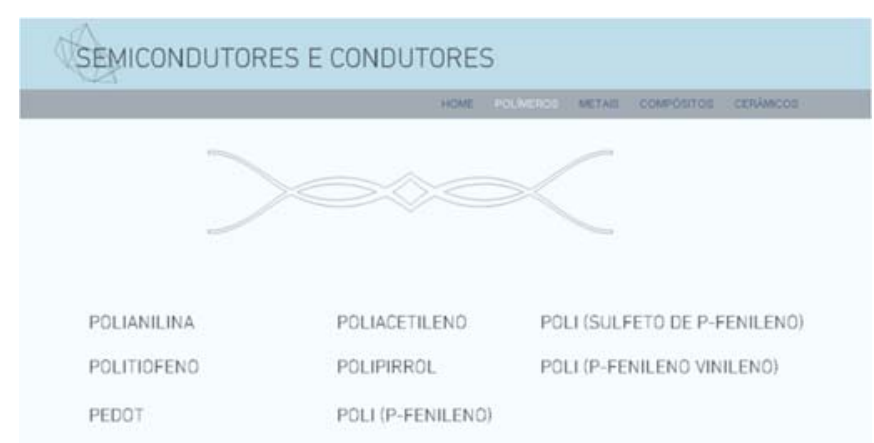

Figura 2. Ao clicar sob algum grupo de materiais no site. 


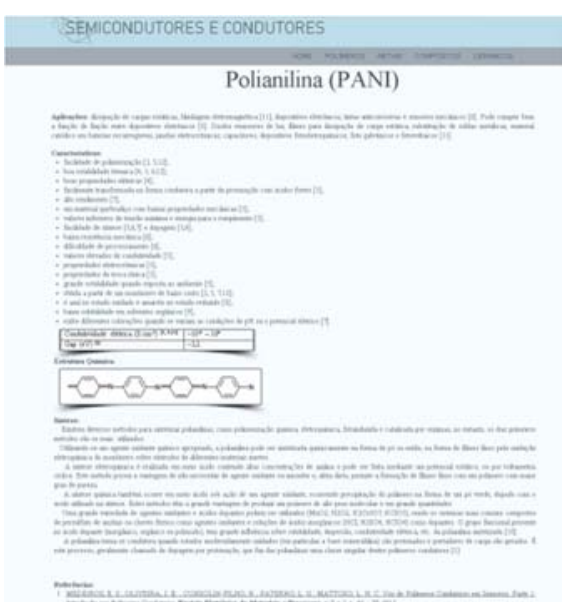

Figura 3. Representação da página do polímero Polianilina no site.

Os materiais disponibilizados no site são elementares para a indústria microeletrônica, uma vez que Maia [7] cita que atualmente direciona-se muita atenção à aplicação de polímeros condutores em dispositivos eletrônicos. Em essência, polímeros condutores são materiais que combinam as propriedades elétricas e ópticas de semicondutores, com as propriedades químicas e mecânicas de polímeros. Por isso, possuem elevado potencial tecnológico, como dispositivos optoeletrônicos e, portanto, figuram centralmente na pesquisa mundial em materiais de alto desempenho.

De acordo com Molisani [2] e Knudsen [8], a grande maioria dos dispositivos eletrônicos recebe um encapsulamento polimérico devido ao baixo custo de produção. Os materiais cerâmicos são usados como material de encapsulamento quando dispositivos eletrônicos operam em ambientes suscetíveis ao ataque químico como, por exemplo, ambientes úmidos. Além disso, Molisani [2] complementa que os materiais cerâmicos apresentam condutividade térmica superior a dos materiais poliméricos, favorecendo o seu uso em dispositivos de alta eficiência que funcionam em alta frequência e/ou alta potência. Os materiais cerâmicos usados como substrato e/ou encapsulamento de dispositivos eletrônicos devem apresentar coeficientes de expansão térmica próximos ao do silício, que é o principal material usado na fabricação de chips.

Segundo Capucci [6] e Brocenschi [9], os materiais compósitos são projetados de modo a combinar propriedades de um ou mais materiais a fim de gerar novos materiais com características desejáveis que seriam difíceis de se obter separadamente por meio dos componentes individuais. Dessa forma, compósitos condutores tornam-se materiais melhorados e que podem ser utilizados em uma gama de aplicações.

Mennucci [4] afirma que o cobre, que é um metal, é o material mais empregado no ramo da indústria eletroeletrônica e de telecomunicações, o que pode ser atribuído à alta condutividade elétrica e boa resistência à corrosão. Devido à sua grande condutividade térmica, o cobre também é usado em trocadores e condutores de calor.

\section{CONCLUSÃO}

Com base no trabalho realizado, espera-se que o banco de dados eletrônico possa ser útil aos interessados na área de materiais semicondutores, uma vez que é uma forma rápida de conter informações e de fácil acesso. Tendo em vista a influência 
dos materiais, é de tamanha importância ter um conhecimento, no mínimo, básico a respeito dos semicondutores, já que estes são indispensáveis para a fabricação de praticamente todos dispositivos eletrônicos que são frequentemente usados no dia a dia das pessoas.

O setor de semicondutores já foi alavancado e deve continuar em ascensão devido ao ingresso de produtos digitais, que exigem uma melhora constante na qualidade. A partir disso, é necessária a utilização de diferentes materiais que possam se adequar às necessidades exigidas pelos equipamentos eletrônicos.

\section{Agradecimentos}

Os autores agradecem ao CNPq através do edital : Chamada $n^{\circ} 18 / 2013$ MCTI/CNPq/SPM-PR Petrobras - Meninas e Jovens Fazendo Ciências Exatas, Engenharias e Computação.

\section{REFERÊNCIAS}

1 W. D. Callister Jr. Ciência e engenharia de materiais: uma introdução. LTC, Rio de Janeiro, 2013, $8^{\mathrm{a}}$ ed.

2 Molisani, André Luiz. Sinterização do nitreto de alumínio com compostos contendo cálcio. Brasil, 2004. Dissertação (Mestrado em Engenharia Metalúrgica e de Materiais) - Universidade de São Paulo, São Paulo, 2004.

3 Sombrio, Guilherme. Fotoluminescência do Nitreto de Silício Não Estequiométrico Depositdo por Sputtering Reativo. Dissertação (Mestrado em Microeletrônica)Universidade Federal do Rio Grande do Sul, 2012.

4 Mennucci, Marina Martins. Estudo da corrosão do cobre em meios de sulfato e de cloreto com auxilio do microeletrodo com cavidade e de uma microcélula. Brasil, 2011. Tese (Doutorado em Engenharia) - Universidade de São Paulo, São Paulo, 2011

5 Martins, Johnny De Nardi. Nanocompósitos condutores de poli (fluoreto de vinilideno)polianilinana-nanotubos de carbono. Brasil, 2013. Tese (Doutorado em Ciência dos Materiais) - Programa de Pós-Graduação em Ciência dos Materiais, Universidade Federal do Rio Grande do Sul, Porto Alegre, 2013.

6 Capucci, Hildo Henrique Grediaga. Investigação da influência de dimercaptanos nas propriedades eletroquímicas de polímeros eletroativos e nanotubos de carbono. Brasil, 2012. Dissertação (Mestrado em Química) - Universidade Federal de Uberlândia, Uberlândia, 2012.

7 Maia, Francisco Carlos Barbosa. Estudo da interação interfacial entre polímeros semicondutores e metais surfactantes. Brasil, 2011. Tese (Doutorado em Ciência) Programa Pós-Graduação em Física, Universidade de São Paulo, São Carlos, 2011.

8 Knudsen, AK. Aluminium Nitride. American Ceramic Society Bulletin. 1995, v.74, n.6, p. 97-98.

9 Brocenschi, R.F. Síntese e Caracterização de Compósitos Polipirrol/ $/ \mathrm{TiO}_{2}$. Monografia (Bacharelado em Química) - Universidade São Francisco, Itatiba, 2007. 